\title{
Erratum to: Refining cryptophyte identification: matching cell fixation methods to FISH hybridisation of cryptomonads
}

\author{
Linda K. Medlin • Sabine Strieben
}

Published online: 15 October 2010

(C) Springer Science+Business Media B.V. 2010

Erratum to: J Appl Phycol

DOI 10.1007/s10811-010-9512-Z

Unfortunately, Prof. Linda K. Medlin's affiliation was incorrect and should appear as shown below.

The online version of the original article can be found at http://dx/doi. org/10.1007/s10811-010-9512-z.

L. K. Medlin $(\bowtie)$

UPMC Univ Paris 06, UMR 7621, LOMIC,

Observatoire Océanologique,

66651 Banyuls/mer, France

e-mail: medlin@obs-banyuls.fr

L. K. Medlin

CNRS, UMR 7621, LOMIC,

Observatoire Océanologique,

66651 Banyuls/mer, France

S. Strieben

Alfred Wegener Institute for Polar and Marine Research,

Am Handelshafen 12,

27570 Bremerhaven, Germany 